\title{
Mudança conceitual de alfabetização e crise da formação
}

\section{Changes in the concept of literacy and the formation crisis}

\section{Cambio conceptual de la alfabetización y la crisis de formación}

\author{
Analice Czyzewski ${ }^{1}$ \\ Maria Terezinha Bellanda Galuch ${ }^{1}$
}

DOI: http://dx.doi.org/10.20435/serie-estudos.v23i47.1113

\begin{abstract}
Resumo: Com o objetivo de refletir sobre o processo de alfabetização no contexto da implementação de políticas públicas no Brasil, a partir da década de 1990, bem como sobre as transformações na organização do mundo do trabalho e suas relações com a educação e a nova forma de se conceber o processo de alfabetização, este texto se insere nas discussões sobre a crise da formação. Compreende-se a alfabetização como um processo complexo e multifacetado, cujo objeto de ensino é o sistema de escrita alfabética considerado, neste estudo, como condição e ponto de partida para o acesso e compreensão do conhecimento registrado sob a forma de textos escritos, o que não significa abrir mão dos demais objetos extralinguísticos para a apropriação da cultura e ampliação do horizonte da compreensão e uso da língua em diversos contextos sociais e culturais, bem como a consolidação do letramento e do desenvolvimento da capacidade de entender a sociedade naquilo que a realidade imediata nega pela simplificação de sua complexidade. Decorre desse entendimento, a opção pela Teoria Crítica da Sociedade para orientar a reflexão. apontando para o contexto de mundialização do capital e da implementação de políticas públicas para a educação que conduzem a uma formação contrária ao desenvolvimento da autonomia.
\end{abstract}

Palavras-chave: alfabetização; políticas públicas; Teoria Crítica; formação.

Abstract: Current paper discusses the schooling and literacy process within the implementation
context of public policies in Brazil since the 1990s and the transformations in the organization of
labor and its relationship with education and the new way to conceive the literacy process. The
text comprises an analysis on the formation crisis. Literacy is a complex and variegated process.
It proposes the teaching of writing as a condition and starting point to access and understand
knowledge registered in written texts. The above does not mean forfeiting other extralinguistic
objects for the appropriation of culture and broadening on comprehension and use of language
in other social and cultural contexts. On the contrary, it highlights the consolidation of literacy and

${ }^{1}$ Universidade Estadual de Maringá (UEM), Maringá, Paraná, Brasil. 
the development of the capacity to understand society within the issues that immediate conditions deny through the simplification of its complexity. The option for the Critical Theory of Society is thus underscored to guide analyses based on the context of the globalization of capital and the implementation of educational public policies that lead towards a formation which is opposed to the development of autonomy.

Keywords: literacy; public policies; Critical Theory; formation.

Resumen: Ese texto discute la crisis de formación en el proceso de alfabetización en el contexto de la implementación de políticas públicas en Brasil desde la década de 1990 y de las transformaciones en las organizaciones del mondo del trabajo y sus relaciones con la educación y la nueva forma de hacer el proceso de alfabetización. Se comprende la alfabetización como un proceso complejo y de muchas facetas cuyo objeto de enseñanza es el sistema de escrita alfabética, visto en ese estudio como una condición y punto de partida para el acceso y comprensión del conocimiento registrado en la forma de textos escritos; lo que no significa dejar de lado los demás objetos extralingüísticos para la apropiación de la cultura y ampliación del horizonte de la comprensión y uso de la lengua en diversos contextos sociales y cultures, así como la consolidación del uso social de la escrita y del desarrollo de la capacidad de comprender la sociedad en lo que la realidad inmediata niega por la simplificación de su complejidad. Por ese entendimiento, la escoja por la Teoría Crítica de la Sociedad sirve para guiar la reflexión haciael contexto de que la mundialización del capital y la implementación de políticas públicas para la educación conducen a una formación opuesta al desarrollo de la autonomía.

Palabras-clave: alfabetización; políticas públicas; Teoría Crítica; formación

\section{INTRODUÇÃO}

Ao refletir sobre o processo de alfabetização no contexto da implementação de políticas públicas implementadas no Brasil a partir da década de 1990, este texto se insere nas discussões sobre a crise da educação.

Compreende-se a alfabetização como um processo complexo e multifacetado cujo objeto de ensino é o sistema de escrita alfabética considerado, neste estudo, como condição e ponto de partida para o acesso e compreensão do conhecimento registrado sob a forma de textos escritos, o que não significa abrir mão dos demais objetos extralinguísticos para a apropriação da cultura e ampliação do horizonte da compreensão e uso da língua, em diversos contextos sociais e culturais, bem como a consolidação do letramento e do desenvolvimento da capacidade de entender a sociedade naquilo que a realidade imediata nega pela simplificação de sua complexidade. Decorre desse entendimento, a opção pela Teoria Crítica da Sociedade para orientar a reflexão aqui apresentada.

Nesse sentido, as mudanças decorrentes do mundo do trabalho precisam ser consideradas para se compreender as requalificações exigidas no âmbito da 
produção da vida material que representam, de forma natural, os interesses do modo de organização capitalista. O trabalho, ao assumir determinada forma de organização, gera questões que tipificam a formação humana. Assim, a sociedade assume sua natureza capital que se move "[...] sem alterarem o regime de propriedade dos meios de produção nem a apropriação da mais-valia sob a forma de lucro privado industrial e financeiro" (COHN, 1986, p. 10).

Essa lógica que perpassa a sociedade e seus indivíduos apresenta-se sob a forma de ideologia responsável pela articulação da consciência social em seus diversos níveis. A Política Educacional, os programas e as ações governamentais são a representação oficial de uma determinada concepção que parece estar inseparável da manutenção e ampliação do eixo exploratório do capital. Isso não significa um simples alinhamento entre os fatores sociais, econômicos, políticos e a educação, mas que a estrutura geral da sociedade perpassa as questões particulares e que o poder do capital está envolvido nas questões educacionais em geral e na alfabetização em específico.

Esses aspectos específicos da educação passam do âmbito social para o âmbito da formação dos sujeitos por meio das instituições sociais, sendo a escola a instituição responsável por conduzir, de forma intencional e sistematizada, o processo educativo e, portanto, a alfabetização. De acordo como Plano Nacional de Educação (BRASIL, 2014), a apropriação da linguagem escrita deve efetivar-se até o terceiro ano de escolarização, destacando-se a alfabetização como a chave de acesso ao conhecimento científico de caráter universal.

No entanto é imperativo salientar que, no contexto de criação e universalização da escola pública nos séculos XIX e XX, evidencia-se a produção de analfabetos funcionais. As dificuldades apresentadas no início do processo de alfabetização arrastam-se pela vida adulta dos sujeitos, não tendo como desvincular tal fato do objetivo percorrido pelo capitalismo, qual seja, o de ofertar nas escolas uma formação que prioriza os saberes úteis necessários à manutenção da sociedade e produção de riquezas - concomitantemente à permanência da desigualdade -, em detrimento da formação de uma consciência autônoma. Assim, podemos dizer que a persistência histórica de problemas que permeiam o processo de alfabetização, expressão da crise formativa nos primeiros anos do ensino fundamental, é também a crise da formação, ou seja, "A crise da formação é a expressão mais desenvolvida da crise social da sociedade moderna" (MAAR, 1995, p. 16). Nesse 
sentido, crise no âmbito da alfabetização e contexto histórico-social mantêm relação recíproca, cuja compreensão pode significar avanço para a tomada de decisões político-pedagógicas.

Para encaminhar essa discussão, este texto está estruturado em duas partes: a primeira é dedicada à reflexão sobre a mudança conceitual da alfabetização no contexto das reformas educacionais no Brasil e sua relação com a crise da educação. Na segunda parte, o foco são as mudanças no mundo do trabalho e suas relações com a educação e a nova forma de se conceber o processo de alfabetização.

\section{A MUDANÇA CONCEITUAL DA ALFABETIZAÇÃO NO CONTEXTO DAS REFORMAS EDUCACIONAIS NO BRASIL}

$\mathrm{Na}$ atualidade, o insucesso de alunos na alfabetização se apresenta como um problema que, no Brasil, a despeito de programas e políticas públicas que buscam solucioná-lo, perdura como expressão da crise da formação que tem acompanhado tanto a expansão de vagas como o aumento do nível de escolaridade dos brasileiros, não se limitando aos anos iniciais do ensino fundamental.

Estudos sobre esse tema (GONTIJO, 2008; SILVA, 2015; SOARES, 2016) apontam para avanços, limites e incongruências na forma de se conceber e encaminhar o processo de alfabetização desde o final do século XIX quando, no Brasil, começou a se intensificar a busca pela consolidação da estrutura educativa e atendimento à demanda social pela escolarização. A discussão sobre a alfabetização, até a década de 1980, vinculava-se ao debate e às teorizações centradas na escolha adequada do caminho para se garantir à criança a aprendizagem da codificação e da decodificação, não estando a função social da escrita no centro dessas discussões. Dessa forma, o letramento e sua interdependência com o processo de alfabetização também não era objeto de estudo da área, tampouco se fazia presente nas cartilhas que sistematizavam propostas de alfabetização que revelavam a polêmica entre métodos de marcha sintética e métodos de marcha analítica.

A partir da década de 1980, a investida contra os problemas no processo de alfabetização começa a se ligar a críticas aos antigos métodos que, durante décadas, foram objeto de disputa. No movimento pela democratização do ensino, aliado à constituição de uma Política Educacional, os estudos construtivistas passaram

a guiar as discussões e ações que envolviam o processo de alfabetização e o fato 
de os alunos não alcançarem o desempenho esperado quanto à aprendizagem. De certa forma, as críticas voltavam-se para os métodos até então utilizados, bem como ao fato de as práticas de alfabetização guiadas por esses métodos não levarem em consideração a função social da escrita. Todavia, como analisa Klein (2002), nessas críticas, o aspecto histórico-social da própria necessidade humana em relação à escrita não era colocado em pauta, ou seja, não se considerava que, na sociedade atual, a escrita não é a única forma de registrar e transmitir uma ideia, haja vista os meios tecnológicos para fazê-los.

Soares (2016) assinala que, simultaneamente à busca por uma resposta ao fracasso no processo de apropriação da língua escrita, ocorre uma mudança conceitual no que se refere à alfabetização. De um processo caracterizado pela apropriação do código, passa-se a um processo que contempla a função social exercida pela escrita, sendo a escola vista como "agência promotora do letramento". Assim, quando a discussão centrava-se na codificação e decodificação como sinônimo de apropriação de apropriação da leitura e da escrita, os métodos de alfabetização, e, portanto, o ensino, era o foco; quando a concepção sobre a função social da escrita se fortalece, esta ganha espaço, e se ampliam os estudos acerca da "psicogênese da língua escrita", cuja centralidade é o "como a criança aprende". A mudança na concepção de alfabetização acabou colocando a ênfase na 'forma' contraditoriamente, pela desmetodização - e secundarizando o próprio conteúdo da alfabetização, embora a crítica voltava-se justamente à forma de se ensinar.

Essa mudança de concepção de alfabetização, amparada por estudos teóricos que concorreram para que o foco se voltasse para aquele que aprende, ou seja, para a ação do sujeito na interação com o objeto de conhecimento, não está restrito a essa área e aos anos iniciais de escolarização, tampouco é gestada na escola e especificamente por pesquisadores e educadores que defendem encaminhamentos didático-pedagógicos para o 'aprender a aprender' (GALUCH; CHOCHICK, 2018). Ela concorre para a formação do pensamento que reforça a concepção de aprendizagem por toda a vida em atendimento ao desenvolvimento de competências e habilidades necessárias ao mundo da flexibilização, ou seja, fortalece a ideia que reitera a sociedade como tal. Nesses termos, a discussão de Adorno (1973) sobre "[...] o processo de produção de ideias e representações" (COHN, 1986, p. 11) leva à compreensão de que a própria mudança, no conceito de alfabetização, aceita como um avanço e rompimento com a perspectiva me- 
cânica de se apropriar a língua escrita, expressa uma transparente necessidade de a sociedade industrial desenvolvida reproduzir-se, ou seja, o "[...] resultado de uma atividade social determinada" (COHN, 1986, p. 12).

Em se tratando de ações políticas na área educacional, um campo específico que expressa a totalidade, a década de 1990 é marco regulatório na produção de documentos e diagnósticos - sob a coordenação de agências internacionais, dentre as quais destaca-se a Organização das Nações Unidas para a Educação, a Ciência e a Cultura (UNESCO) - destinadas a orientar reformas educativas nos países periféricos cujos direcionamentos teóricos, práticos e políticos são consonantes. Assim, a reestruturação do Estado brasileiro, pode-se dizer, representa a resposta no sentido de atender a recomendações apresentadas em documentos de agências internacionais, que, ao proporem 'reformas' em diferentes âmbitos, têm como objetivo manter a sociedade nas mesmas bases materiais, já que levam à crença de que cada sujeito poderá superar suas dificuldades à medida que desenvolver competências e autonomia para resolver conflitos, estar preparado para correr riscos e enfrentar desafios; isso envolve a competência de usar a escrita em diferentes situações da vida. Nessa perspectiva, programas de formação continuada de professores na área da alfabetização também são um componente da política educacional gestada nesse contexto e comandada pelo próprio capitalismo na figura das agências que fomentam a implementação desses programas e controlam a formação.

A discussão sobre as mudanças na concepção de alfabetização, nesse movimento de reestruturação do Estado e preservação da sociedade, leva a se pensar sobre a crise da formação pela renúncia do conhecimento já sistematizado considerado como sinônimo de tradicional e, por isso, ultrapassado e desnecessário porque impróprio à adaptação à realidade. Esse abandono do conhecimento sobre e no processo de alfabetização ou "alienação da memória" não está alheio ao desaparecimento do "tempo concreto [...] da produção industrial" (ADORNO, 1995, p. 33) que "[...] procede sempre em ciclos idênticos e pulsativos, potencialmente de mesma duração, e praticamente não necessita mais da experiência acumulada" (ADORNO, 1995, p. 33).

Essa nova forma de conceber a alfabetização racionaliza o processo de modo que a motivação para aprender se torna externa ao conteúdo da aprendizagem (GALUCH; CHOCHICK, 2018). A alfabetização pautada nos métodos para ensinar o 
sistema de escrita alfabética também representava conhecimento social acumulado que não se aprende pela simples relação da criança com diversos materiais escritos e por meio de um ensino centrado no próprio aluno. Ao se voltar especificamente para a utilidade da leitura e da escrita, negligencia-se o conhecimento "[...] do sistema alfabético-ortográfico e das convenções da escrita, objeto que demanda processos cognitivos e linguísticos específicos e, portanto, desenvolvimento de estratégias específicas de aprendizagem e, consequentemente, de ensino [...]" (SOARES, 2016, p. 29). Isso reduz a possibilidade da própria experiência (ADORNO, 1995) e abre campo fértil para o ensino que enfatiza a aprendizagem do processo de aprender em detrimento do conteúdo da aprendizagem, expressando que "[...] a racionalização progressiva dos procedimentos da produção industrial elimina junto aos outros restos da atividade artesanal também categorias como a da aprendizagem, ou seja, do tempo de aquisição da experiência do ofício" (ADORNO, 1995, p. 33).

Portanto observa-se a ausência de incorporação do conhecimento sistematizado sobre os métodos e sobre a própria alfabetização e a adesão a novas propostas, sob a justificativa de se romper com o tradicionalismo e implementar uma forma de ensino em que o aluno conduza a sua própria aprendizagem. Essa inversão acaba por ser uma forma de negar a possibilidade de desenvolvimento da consciência e da autonomia que poderiam levar ao entendimento de que a sociedade limita a própria consciência; pela justificativa de um "novo" ensino para uma "nova" realidade, perde-se a possibilidade de compreensão de que o sentimento de pertencimento é um dos meios de fortalecimento da ordem existente, ou seja, uma formação a serviço das formas de controle (MARCUSE, 1967). Nos termos de Adorno (1995, p. 33): "Quando a humanidade se aliena da memória, esgotando-se sem fôlego na adaptação ao existente, nisto reflete-se uma lei objetiva de desenvolvimento".

Assim, quando as discussões sobre a alfabetização limitam-se à forma, impossibilita-se pensar sobre as condições objetivas nas quais estão inseridos, inclusive, os programas oficiais de orientação para a alfabetização. Em última instância, a nova forma de se conceber a alfabetização e a consequente forma de organizar o seu ensino é um dos mecanismos da própria sociedade para formar homens bem ajustados ao contexto, contrariando a educação para a emancipação (ADORNO, 1995). 


\section{TRABALHO, EDUCAÇÃO E NOVA FORMA DE SE CONCEBER A ALFABETIZAÇÃO}

No contexto socioeconômico e cultural da racionalidade técnica, a educação é fenômeno preponderante na formação da consciência dos sujeitos (ADORNO, 1995); todavia, quando vinculada tão somente a responder à demanda da sociedade capitalista, aporta como mecanismo de dominação. "[...] Adorno aponta para a força da escola como instituição formalmente constituída. Se assim é, esta escola deve ser orientada para a construção de seres emancipados. Em suas palavras exatas: 'não se deve negar a importância da educação' [...]" (ZUIN; PUCCl; RAMOS-DE-OLIVEIRA, 2000, p. 156).

Desse modo, explicita-se que à escola cabe a tarefa de conduzir, de forma intencional e sistemática, a educação dos indivíduos, tal como defende Saviani (1991, p. 23), para quem "A Escola existe, pois, para propiciar a aquisição dos instrumentos que possibilitam o acesso ao saber elaborado (ciência), bem como o próprio acesso aos rudimentos desse saber". A alfabetização como um dos instrumentos primordiais para que o sujeito acesse o saber elaborado é o marco formal de inserção dos sujeitos na cultura letrada da sociedade contemporânea. Assim, a escola é a instituição que "[...] visa à formação cultural e científica, isto é, ao domínio do saber sistematizado mediante o qual se promove o desenvolvimento de capacidades intelectuais, como condição de assegurar o direito à semelhança, à igualdade" (LIBÂNEO, 2012, p. 26).

As falhas decorrentes do processo de alfabetização entendidas como fracasso ou dificuldade é a própria crise da educação e da formação, revelando o não cumprimento da função da escola que é a de possibilitar o acesso à cultura e contribuir para a reflexão sobre as condições objetivas que estão na base da barbárie para que, dessa forma, possa se desenvolver a consciência que resiste a essas condições (ADORNO, 1995). No âmbito de uma escola que deixa de cumprir a sua função, Libâneo (2012), ao analisar as políticas educacionais a partir dos anos 1990, denuncia a "[...] dualidade da escola pública brasileira atual, caracterizada como uma escola do conhecimento para os ricos e como uma escola do acolhimento social para os pobres" (LIBÂNEO, 2012, p. 13).

Portanto as mudanças decorrentes da organização do processo produtivo permitiram implementar, a partir da década de 1990, um conjunto de reformas na esfera da administração do Estado brasileiro que atingiram a gestão educacional 
e também influenciaram a formulação de políticas para a alfabetização, alterando a prática e a organização do trabalho pedagógico.

Tal como mencionado no item anterior deste artigo, nesse contexto de mudanças, a alfabetização passou por uma mudança conceitual, momento em que estudos acerca da psicogênese da língua escrita ganharam força e chegaram ao Brasil com pesquisas de Ferreiro e Teberosky (1999), amplamente divulgadas e conhecidas no domínio escolar como propostas construtivistas, advogando em favor de uma prática que busca compreender "como a criança aprende". Dessa forma, foi sendo entendido que a alfabetização precisava ser complementada com práticas de letramento.

Nesse movimento, denominado por Soares (2016) como movimento pendular que traz uma significativa mudança teórica e prática na condução do processo de alfabetização, o letramento torna-se protagonista em documentos e referenciais para a educação básica. A compreensão desse movimento dá-se quando se destaca o vínculo entre trabalho, processo de globalização, educação e alfabetização. O trabalho como "[...] atividade realizada todos os dias, todas as horas que promove o intercâmbio material entre o gênero humano e a natureza, tornando-se o elemento que promove a manutenção da vida humana" (FARIAS, 2010, p. 10). Todavia a forma como o trabalho é organizado para suprir as necessidades da vida humana sofreu e sofre alterações em meio à criação de necessidades que, a despeito do mal que provocam aos homens, voltam-se para a reprodução da própria sociedade.

Nesses termos, as transformações na organização da produção influenciam e determinam a Política Social dos países, sendo a educação "[...] uma política pública social, uma política pública de corte social" (HOFLING, 2001, p. 31). Assim, "[...] as políticas sociais e a educação se situam no interior de um tipo particular de Estado" (HOFLING, 2001, p. 31). Para a autora, "é impossível pensar Estado fora de um projeto político e de uma teoria social para a sociedade como um todo" (HOFLING, 2001, p. 32). Em consonância com a autora, destaca-se que este é um dos aspectos fundamentais para compreender as políticas em consequência os programas para alfabetização.

Na década de 1970, o Estado capitalista enfrentou uma grave crise provocada pela saturação do modelo Taylorista/Fordista caracterizado pela produção rígida e padronizada em larga escala, queda nas taxas de lucro, e o declínio do 
Estado de bem- estar social2 ${ }^{2}$, forjando um processo de reorganização dos processos produtivos. Teses liberais se fortalecem e se apresentam como mote para responder à crise, cujas mudanças previam "menos Estado e mais mercado", ou seja, a prevalência do capital. Intelectuais reconhecidos como Hayek (1977) e Friedman (1997) perpetraram a defesa do individualismo e da regulação das relações via mercado, proferindo uma enfática crítica à intervenção estatal, em favor da cooperação espontânea dos indivíduos para realizar um ajuste estrutural. Essas ideias foram documentadas no Consenso de Washington, em 1989, estruturando um programa de reformas para os países em desenvolvimento tendo como meta o ajuste macroeconômico.

Nesse cenário, ganha impulso o processo de globalização que, para Dale (2004, p. 436), pode ser definido como "um conjunto de dispositivo político-econômicos para a organização da economia global, conduzido pela necessidade de manter o sistema capitalista, mais do que por qualquer outro conjunto de valores".

A esse processo global flexível no campo estatal corresponde a privatização, a desregulação de direitos trabalhistas e a flexibilização dos processos de trabalho que, no plano ideológico, valoriza o individualismo e recorre aos processos de gestão e participação autônomas como técnicas para alcançar a coesão e o consenso.

Como conseqüência, o tipo de globalização que se opera nesse contexto neoliberal irá transformar radicalmente a ação do Estado no campo das políticas sociais. A tese do fim da história e do fim das ideologias é um pressuposto importante, uma vez que se trata de estabelecer a hegemonia de um pensamento único, contra o qual nada há que possa ser feito. (PALMA FILHO, 2007, p. 4).

A globalização e a flexibilização da produção auxiliada pela tecnologia possibilitaram a abertura de novos mercados, quando novas habilidades e competências passam a ser exigidas do trabalhador, interferindo diretamente nas propostas e práticas pedagógicas, inclusive, na alfabetização, que também se flexibiliza para atender às novas exigências formativas que se voltam para a utilidade. Dessa forma:

[...] conceitos como 'autonomia', 'comunidade educativa', 'projeto educativo', continuarão a ser convocados, com maior frequência, mas como instru-

\footnotetext{
${ }^{2}$ O Estado de Bem-Estar Social foi implementado após a II Guerra Mundial, como proposta e resposta à crise econômica da década de 1930. Com o objetivo de reconstruir a economia dos países afetados pela guerra, o Estado fez investimentos nas áreas sociais e de infraestrutura.
} 
mentos essenciais de uma política de modernização e racionalização, como metáforas capazes de dissimularem os conflitos, de atuarem a igualdade e o consenso e a harmonia, como resultado ou artefatos, e não como processos e construções coletivas. (LIMA, 2002, p. 31).

Nesse mesmo período, ocorrerem grandes conferências que reuniram países para a discussão de orientações para reformas educacionais dos países em desenvolvimento. Apoiadas no discurso da ineficiência do estado, as orientações e propostas de organismos internacionais, muitas delas apresentadas sob a forma de relatórios, encontraram campo fértil na década 1990, influenciando a organização do sistema educacional brasileiro, inclusive direcionando os debates para definir a Lei de Diretrizes e Bases da Educação Nacional, promulgada em dezembro de 1996, e documentos subsequentes que definem objetivos para a formação, incluindo a formação de professores. Destaca-se que a Declaração de Jomtien "Educação para Todos" foi referencial para a constituição da Política Educacional na América Latina e Caribe. Também foram definidos aspectos teóricos e a agenda para as reformas educacionais que tinham como foco a educação básica na perspectiva de instrumento para combater a pobreza, porém sem mencionar as relações sociais que determinam as desigualdades.

A partir da compreensão da relação existente entre organização do trabaIho e educação, é possível o entendimento da natureza das políticas públicas e das forças que detêm o controle do processo de modo que se possa visualizar o papel da educação em uma "sociedade regida pelas leis do mercado, no que diz respeito ao processo de acumulação capitalista e de legitimação social" (PALMA FILHO, 2007, p. 11). Diante dessas proposições e reformas educacionais, a alfabetização figura como protagonista, continuando no foco de debates, embates e questionamentos quanto à sua eficiência e importância no processo formativo dos escolares. O Plano Nacional de Educação para a década 2014-2024, que define diretrizes, metas e estratégias para a Política Educacional, também reconhece e quantifica o problema da alfabetização:

O fenômeno do analfabetismo funcional, cuja raiz é encontrada nas séries iniciais do ensino fundamental, expressa dificuldades presentes nos processos de escolarização, mostrando o seu distanciamento de adequados padrões de qualidade. Dados do Censo Demográfico de 2010 revelaram que $15,2 \%$ das crianças brasileiras com 8 anos de idade que estavam cursando o ensino fundamental eram analfabetas. (BRASIL, 2014, p. 26). 
De forma geral, os programas e ações propostos pelo Estado capitalista visam a minimizar os problemas enfrentados no ciclo da alfabetização, porém a gama de questões referentes à qualidade do ensino ainda persiste e aponta para necessidade de políticas públicas efetivas, ou seja, políticas de estado, em substituição a políticas focalizadas. Nessa perspectiva, as discussões acerca do processo de alfabetização também buscam uma proposta ou uma metodologia que possam resolver a questão, como, por exemplo, o embate entre os métodos e a posterior desmetodização.

Retoma-se aqui a questão sobre a mudança do eixo conceitual no processo de alfabetização para relacioná-lo ao processo mais amplo de globalização, flexibilização dos processos de produção e de formação. Assim, percebe-se que a alfabetização está envolvida em um conjunto de fatores que ultrapassa as questões conceituais da área específica e práticas relativas ao objeto de ensino. A alfabetização que, aparentemente, avança e se amplia por buscar romper com o aspecto mecânico da decodificação e codificação, limita a possibilidade de formação para a autonomia, uma vez que se reduz à forma de aprender, impedindo a própria experiência. Isso pode ser evidenciado em propostas que:

[...] compreendem a alfabetização como um processo intencional, complexo e interdisciplinar: uma verdadeira proposta de educação integral que deve inserir a criança em um ambiente seguro, lúdica e motivador de novos aprendizados, articulado com a vivência de valores como curiosidade, criatividade, respeito às diferenças, espírito investigativo, trabalho cooperativo, resiliência, resolução de problemas e outros que preparam o indivíduo para ser, viver e conviver no século XXI. (BRASIL, 2017, p. 11, grifo nosso).

Neste sentido, é inevitável relacionar os objetivos da alfabetização apresentados nesse documento com o proposto pelo Relatório para a UNESCO da Comissão Internacional sobre Educação para o século XXI como os quatro pilares para a educação: "aprender a conhecer", "aprender a fazer", "aprender a conviver" e "aprender a ser" (DELORS, 1996). Retomando: a mudança do eixo conceitual no processo de alfabetização não significa uma simples alteração de termo, tampouco o simples abandono de métodos para a condução desse processo, mas uma mudança conceitual que, quando observada no movimento histórico que a produziu, indica uma interferência das condições objetivas na organização do ensino e nos objetivos de formação. 
Assim, não se trata mais de manter aquela velha escola assentada no conhecimento, isto é, no domínio dos conteúdos, mas de conceber uma escola que valorizará formas de organização das relações humanas nas quais prevaleçam a integração social, a convivência entre diferentes, o compartilhamento de culturas, o encontro e a solidariedade entre as pessoas. (LIBÂNEO, 2012, p. 17).

Concebe-se, assim, uma escola que se organiza para atender às "necessidades básicas de aprendizagem", convertendo facilmente seu objetivo em um "pacote restrito e elementar de destrezas úteis para a sobrevivência e para as necessidades imediatas e mais elementares das pessoas [...] conhecimentos utilizáveis para a vida prática" (LIBÂNEO, 2012, p. 18). A alfabetização como parte do processo de escolarização e do ensino também se restringiu a esse "pacote de destrezas úteis", ao focar o uso social da escrita de modo a secundarizar a alfabetização e as técnicas nela envolvidas. Não se trata de uma opção entre a alfabetização ou o uso social da escrita, mas de compreender que:

[...] não é apenas a alfabetização [...] que assegura à criança, em seus primeiros anos de escolarização, a entrada no mundo da cultura escrita. [...] a alfabetização é uma das três facetas da aprendizagem inicial da língua escrita, necessária, mas não suficiente, porque esta só se completa se integrada com as facetas interativa e sociocultural, estas duas constituindo o letramento (SOARES, 2016, p. 345, grifos da autora).

O conjunto de elementos apresentados no decorrer deste texto não é a representação da totalidade de mecanismos e relações existentes na sociedade. A relação que se pretendeu estabelecer vincula-se ao contexto de produção e mundialização do capital que, viabilizado pelo processo de globalização, capitaneado e conduzido pelos organismos internacionais, por meio das políticas públicas para a educação, promove um tipo de formação contrária à autonomia do indivíduo social, ou seja, "[...] ao indivíduo livre e radicado em sua própria consciência, ainda que não tivesse deixado de atuar na sociedade e sublimasse seus impulsos" (ADORNO, 1996, p. 392).

Nesse sentido, a alfabetização deveria conter o caráter promotor dessa autonomia, no entanto, sem desconsiderar os avanços, impera a disputa ora conceitual, ora política, que sofre múltiplas influências e colabora mais no sentido do ajustamento do indivíduo ao sistema do que no da formação humana. De acordo com Adorno (1996): 
Se na idéia de formação ressoam momentos de finalidade, esses deveriam, em conseqüência, tornar os indivíduos aptos a se afirmarem como racionais numa sociedade racional, como livres numa sociedade livre. No modelo liberal, isso seria tanto melhor atingido quanto mais cada um estivesse formado por si mesmo. E quanto menos as relações sociais, em especial as diferenças econômicas, cumprem esta promessa, tanto mais energicamente se estará proibido de pensar no sentido e na finalidade da formação cultural. Nesse sentido, nem se pode denunciar que ela, sozinha, não garante uma sociedade racional. Não se quer liberar a esperança, desde o princípio enganosa, de que ela poderia extrair de si mesma e dar aos homens o que a realidade Ihes recusa. O sonho da formação - a libertação da imposição dos meios e da estúpida e mesquinha utilidade - é falsificado em apologia de um mundo organizado justamente por aquela imposição. No ideal de formação, que a cultura defende de maneira absoluta, se destila a sua problemática. (ADORNO, 1996, p. 392).

As mudanças que se operam na esteira produtiva do capital demandam novas habilidades e competência que passam a figurar no rol de exigências para que o indivíduo possa trabalhar e manter-se vivo; essas exigências vinculam-se aos sistemas de educação, e, como foi apresentado mediante o contexto, são fatores determinantes também para a alfabetização, que muda o foco para o uso que dela se faz. Assim, a formação cultural e "[...] A diferença sempre crescente entre o poder e a impotência sociais nega aos impotentes - e tendencialmente também aos poderosos - os pressupostos reais para a autonomia que o conceito de formação cultural ideologicamente conserva" (ADORNO, 1996, p. 394). Ao considerar a alfabetização como requisito para a entrada formal do sujeito na cultura letrada, é imprescindível observar que temos um processo de alfabetização que, mesmo diante de metas e estratégias, não consegue alfabetizar letrando as crianças nos anos iniciais do ensino fundamental, perpetuando uma questão que segue complexa e contraditória.

\section{CONSIDERAÇÕES FINAIS}

Guiando-se pela relação entre as condições objetivas e a educação, neste estudo, depreende-se que ao processo de flexibilização no âmbito dos processos de organização da produção corresponde a flexibilização também do processo de alfabetização que se faz presente a partir da última década do século XX, marco para a implementação, no Brasil, de um conjunto de reformas educacionais nos 
diferentes níveis de ensino. Portanto a nova concepção de alfabetização, em que a ideia de uso da escrita, por vezes, se sobrepõe à sua própria apropriação, relaciona-se a um conjunto de fatores extrapedagógicos que dão forma à crise da educação e revela que as reformas que se fazem sem compreendê-los acabam por promover uma formação que negligencia o acesso à cultura e, portanto, deixa de ser o alimento para o indivíduo se opor a esses próprios fatores (ADORNO, 1996), justamente por considerarem que a forma de se conceber a alfabetização faz parte do "cipoal" social (ADORNO, 1995).

Sem a pretensão de esgotar o tema, a análise evidencia a importância de se compreender o conjunto amplo e complexo de fatores que movem a organização capitalista e, portanto, interferem e definem a educação em geral e aqui, em específico, o processo de alfabetização.

\section{REFERÊNCIAS}

ADORNO, Theodor W. Teoria da semicultura. Educação e Sociedade, Campinas, SP, ano 17, n. 56, p. 388-411, set./dez. 1996.

ADORNO, Theodor W. Educação e emancipação. Rio de Janeiro: Paz e Terra, 1995.

BRASIL. Pacto Nacional pela Alfabetização na Idade Certa - PNAIC. Brasília, DF: Ministério da Educação, 2017. Disponível em: <http://pacto.mec.gov.br/images/pdf/doc_orientador/ doc_orientador_versao_final.pdf>. Acesso em: 30 nov. 2017.

. Ministério da Educação. Plano Nacional de Educação - PNE. Brasília, DF: Câmara dos Deputados, 2014.

COHN, Gabriel. Adorno e a teoria crítica da sociedade. In: COHN, Gabriel. Theodor W. Adorno: sociologia. São Paulo: Ática, 1986. p. 7-30.

DALE, Roger. Globalização e educação: demonstrando a existência de uma "cultura educacional mundial comum ou localizando uma "agenda globalmente estruturada para a educação". Educação \& Sociedade, Campinas, SP, v. 25, n. 87, p. 423-60, maio/ago. 2004. Disponível em: <http://www.scielo.br/pdf/es/v25n87/21464.pdf>. Acesso em: 7 dez. 2017.

DELORS, Jacques. Educação: um tesouro a descobrir. Relatório para a Unesco da Comissão Internacional sobre a Educação para o século XXI. Brasília: CNPq/IBICT/UNESCO, 1996. Disponível em: <http://unesdoc.unesco.org/images/0010/001095/109590por.pdf>. Acesso em: 7 dez. 2017.

FARIAS. Tarcísio Fagner Aleixo. O conceito de trabalho nos Manuscritos EconômicoFilosóficos de Karl Marx. 2010. 119 f. Dissertação (Mestrado em Filosofia)- Universidade 
Federal da Paraíba (UFPB), João Pessoa, 2010. Disponível em: <http://tede.biblioteca. ufpb.br/bitstream/tede/5674/1/arquivototal.pdf>. Acesso em: 7 dez. 2017.

FERREIRO, Emilia; TEBEROSKY, Ana. Psicogênese da língua escrita. Porto Alegre: Artmed, 1999.

FRIEDMAN, Milton. Capitalismo e liberdade. São Paulo: Arte Nova, 1997.

GALUCH, Maria Terezinha Bellanda; CROCHICK, José Leon. Formação cultural, ensino, aprendizagem e livro didático para os anos iniciais do ensino fundamental. Maringá, PR: EDUEM, 2018.

GONTIJO, Claudia Maria. A escrita infantil. São Paulo: Cortez, 2008.

HAYEK, Friedrich. O caminho da servidão. Porto Alegre: Globo, 1977.

HÖFLING, Eloisa de Mattos. Estado e políticas (públicas) sociais. Cadernos Cedes, Campinas, SP, ano XXI, n. 55, p. 30-41, nov. 2001. Disponível em: <http://www.scielo.br/ pdf/ccedes/v21n55/5539.pdf>. Acesso em: 7 dez. 2017.

KLEIN, Lígia Regina. Alfabetização: quem tem medo de ensinar. 4. ed. São Paulo: Cortez; Campo Grande: Editora da UFMS, 2002.

LIBÂNEO, José Carlos. O dualismo perverso da escola pública brasileira: escola do conhecimento para os ricos, escola do acolhimento social para os pobres. Educação e Pesquisa, São Paulo, v. 38, n. 1, p. 13-28, jan./mar. 2012. Disponível em: <http://www.scielo.br/ pdf/ep/v38n1/aop323.pdf>. Acesso em: 6 dez. 2017.

LIMA, L. Modernização, racionalização e optimização: perspectivas neotayloristas na organização e administração da educação. In: LIMA, L; AFONSO, A. (Org.). Reformas da educação pública: democratização, modernização, neoliberalismo. Porto, Portugal: Afrontamento, 2002. p. 17-44.

MAAR, Wolfgang Leo. À guisa de introdução: Adorno e a experiência formativa. In: ADORNO, Theodor W. Educação e emancipação. São Paulo: Paz e Terra, 1995. p. 11-28.

MARCUSE, Herbert. A ideologia da sociedade industrial. Rio de Janeiro: Zahar, 1967.

PALMA FILHO, J. C. Impactos da globalização nas políticas públicas de educação. In: PALMA FILHO, J. C.; TOSI, P. G. (Org.). Política educacional. 1. ed. São Paulo: Páginas \& Letras, 2007. v. 01, p. 7-20. Disponível em <https://acervodigital.unesp.br/bitstream/123456789/36/4/ D03_Impactos_Globaliza\%C3\%A7\%C3\%A3o.pdf>. Acesso em: 6 dez. 2017.

SAVIANI, Dermeval. Pedagogia histórico-crítica: primeiras aproximações. 2. ed. São Paulo: Cortez/Autores Associados, 1991.

SILVA, Mariza Vieira da. História da alfabetização no Brasil: sentidos e sujeito da escolarização. Campinas, SP: Editora Unicamp, 2015.

SOARES, Magda Becker. Alfabetização: a questão dos métodos. São Paulo: Contexto, 2016. 
ZUIN, A. A. S.; PUCCI, B.; RAMOS-DE-OLIVEIRA, N. Adorno: o poder educativo do pensamento crítico. Petrópolis, RJ: Vozes, 2000.

\section{Sobre as autoras:}

Analice Czyzewski: Professora colaboradora do Departamento de Fundamentos da Educação da Universidade estadual de Maringá (UEM), campus sede, Maringá, Paraná, Brasil; Doutoranda em Educação (PPE/UEM); Mestre em Educação (PPE/ UEM). E-mail: analicefer@hotmail.com

Maria Terezinha Bellanda Galuch: Professora do Departamento de Teoria e Prática da Educação e do Programa de Pós-Graduação em Educação da Universidade Estadual de Maringá (UEM); Doutora em educação- PUC/SP (2004), Pós- doutorado- Instituto de Psicologia- USP (2014).E-mail: galuch@brturbo.com.br

\section{Recebido em setembro de 2017}

Aprovado em dezembro de 2017 
